\title{
Atypical guttural pouch mycosis in three horses
}

\author{
James L Carmalt' and Keith E. Baptiste ${ }^{2}$
}

Department of Large Animal Clinical Services, Western College of Veterinary Medicine, University of Saskatchewan, Saskatoon, Canada ${ }^{1}$ and Department of Veterinary Pathology, Faculty of Veterinary Science, The University of Liverpool, Leahurst, Gt. Britain²

\begin{abstract}
Summary
Three horses presented with clinical signs ranging from an intermittent cough, swollen neck and in one case suggestive of esophageal obstruction. A complete physical examination, upper airway endoscopy and microbiological examination revealed atypical guttural pouch mycosis in that no artery was associated with the fungal mass. Fungal organisms isolated from these cases were Rhizopus spp, Aspergillus nidulans, Penicillium spp, Mucor spp, Chrysosporium spp, and Alternaria spp. All cases were treated medically by local irrigation on a daily basis using a $0.9 \%$ or $1.7 \%$ enilconazole. Whilst the most successful treatment for guttural pouch mycosis is surgical occlusion of the artery associated with the fungal mass, the authors suggest that this represents a skewed population including only horses that present for epistaxis. These cases illustrate the importance of routine guttural pouch endoscopy as part of a complete upper airway examination in the horse. Medical management of early gutturomycosis is a tenable alternative to surgery with the caveat that the surgical option must be exercised in cases of epistaxis or fungal mass involving an artery.
\end{abstract}

Keywords: Guttural pouch, mycosis, equine, medical therapy, atypical

\begin{abstract}
Atypische Luftsackmykose bei drei Pferden
Es wurden drei Pferde mit den klinischen Symptomen intermittierender Husten, geschwollenem Nacken und in einem Fall Verdacht auf Schlundverstopfung untersucht. Die Allgemeinuntersuchung, Endoskopie der oberen Atemwege und mikrobiologische Untersuchung führten zur Diagnose Luftsackmykose. Untypisch war, dass in keinem der Fälle eine Arterie in die mykotischen Plaques involviert war. Es wurden Rhizopus spp., Aspergillus nidulans, Penicillium spp., Mucor spp., Chryosporium spp. und Alternaria spp. isoliert. Alle Patienten wurden sofort mit sofort mit täglichen Luftsackspuelungen mit 0,95\%iger bzw. 1,7\%iger Enilconalzollösung behandelt. Die 1,7\%ige Lösung ergab eine schnellere Heilung als die 0,9\%ige, was zum Teil darauf zurückzuführen ist, das sie aufgrund ihrer hoeheren Viskositaet laenger im Luftsack verblieb. Bisher stellte der Verschluss der Arterie, die mit den mykotischen Plaques verbunden war die erfolgreichste Therapie dar. Die Autoren sind allerdings der Meinung, dass dies nur Pferde betrifft, die wegen Epistaxis vorgestellt werden und diese eine Randpopulation darstellen. Die vorliegenden Fälle machen deutlich, wie wichtig die routingemaeßige Luftsackendoskopie bei der Untersuchung der oberen Atemwege des Pferdes ist. Die medikamentöse Therapie von Luftsackmykosen in einem frühen Stadium ist ein durchaus tragbare Alternative zum chirurgischen Eingriffe unter Beachtung der Tatsache, dass eine Operation in Fällen von Epistaxis oder Pilzplaques verbunden mit einer Arterie unumgänglich ist.
\end{abstract}

Schlüsselwörter: Luftsack, Mykose, Pferd, Therapie, atypisch

\section{Introduction}

The air-filled guttural pouches are large diverticuli of the auditory tubes, found in horses, tapir (Turner 1850), rhinoceros, hyrax (Brandt 1863), six species of small bats and the South American Forest mouse (Heteromys anomalus) (Hinchcliffe and Pye 1969). In the horse, possessing the largest guttural pouch, they occupy a considerable area extending from the roof of the pharynx to the base of the skull and from the atlanto-occipital joint to the pharyngeal recess. Theories have been postulated as to the function of the pouches; however, recent evidence demonstrates a role of the equine guttural pouch in selective brain cooling (Baptiste et al. 2000). The unique and intricate relationship of blood vessels, nerves and other surrounding anatomical structures explains how guttural pouch diseases are susceptible to serious and sometimes fatal outcomes (Otto et al. 1995; Engelke et al. 1997). Guttural pouch mycotic infections cause a variety of clinical signs depending on the integrity of the surrounding neurova- scular supply. Thus, horses may exhibit episodes of spontaneous unilateral or bilateral epistaxis, nasal discharge, dysphagia (Cook 1966; Kipar and Frese 1993), laryngeal hemiplegia, Horner's syndrome (Cook 1968), abnormal head extension, head shaking (Lane and Mair 1987), parotid swelling, ocular changes (Hatziolos et al. 1975), facial nerve paralysis, mycotic encephalitis (Wagner et al. 1978; McLaughlin and O'Brian 1986) and atlanto-occipital infection (Dixon and Rowlands 1981; Walmsley 1988) with or without other cranial nerve deficits (Raker 1976; Freeman 1980). In some cases, no signs are seen (Cook 1971). There appears to be no age or sex predilection for guttural pouch mycosis with the youngest case reported in a 3-month-old foal (Ryan et al. 1992).

The most common fungus to invade the pouch is Aspergillus including A. fumigatus (Guillot et al. 1996), A. nidulans (Johnson et al., 1973; Rawlinson and Jones 1978) and A. 
ochraceus (Gresti 1993). Other rare fungal elements include Candida, Penicillium (Grabner 1987) and Mucor (Freeman et al. 1989). In the majority of cases, fungal growth appears to have a predilection for the caudodorsal part of the medial pouch overlying the internal carotid artery (Cook 1966) or maxillary artery along the lateral compartment (Bjorklund and Palsson 1970; Smith and Barber 1984). From the former

Fig 1 Endoscopic view of the right guttural pouch showing fungal plaque invasion of the medial septum.

Endoskopische Ansicht des rechten Luftsacks mit invasiver Plaquebildung am medialen Septum.

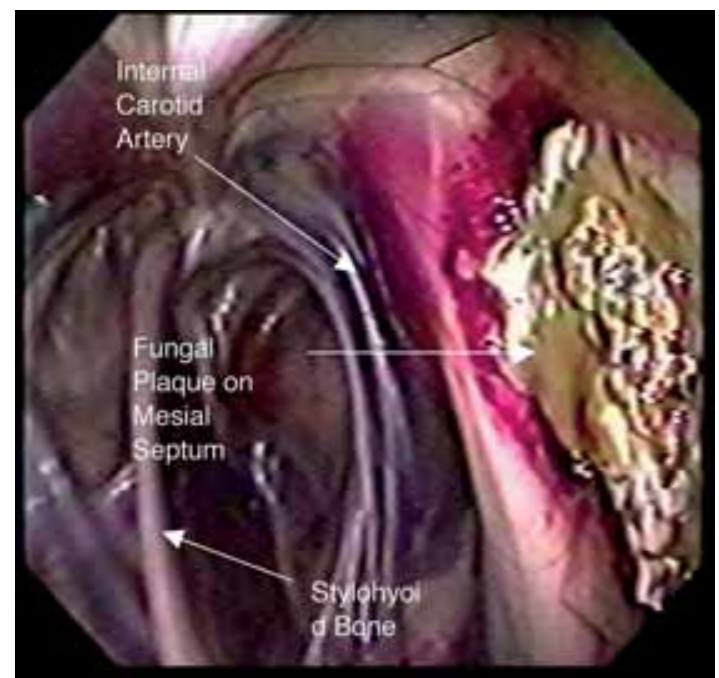

position it may spread forward to the pharyngeal recess (Greet 1987), laterally to the lateral compartment, medially to the contralateral guttural pouch (Jacobs and Fretz 1982) and ventrally onto the stylohyoid bone (Cook 1966). The purpose of this case series is to present atypical cases of guttural pouch mycosis in that major arteries were not involved, and the outcomes following medical therapy.

\section{Case 1}

A 3-year-old, 415-kg (913-lb) American Quarter horse filly was presented to the Western College of Veterinary Medicine (WCVM) with a five-month history of depression, intermittent coughing, weight loss and reduced appetite. There was no history of nasal discharge, quidding or exercise intolerance. Vaccination and deworming history were current.

On clinical evaluation the filly was bright, alert and responsive. Rectal temperature and heart rate were normal, and tachypnea (48 breaths/min). Tracheal palpation did not elicit coughing but there was an abdominal effort during breathing and slight nostril flaring. Thoracic auscultation revealed increased bronchovesicular sounds bilaterally, more marked on the left hemi-thorax both cranio-ventrally and caudo-dorsally. Chest percussion revealed no fluid line or pleurodynia. A re-breathing bag further accentuated the pulmonic findings. Cardiac auscultation was unremarkable.

A complete blood count revealed a leukocytosis, (14.6x109 $/ L$; reference range 5.5 - 12.5) and neutrophilia, $\left(10.95 \times 10^{9} / \mathrm{L}\right.$; reference range 2.7 - 6.7). Endoscopic examination of the upper respiratory tract was performed using a videoendoscope (Olympus GIF Type 130, Olympus Corpo- ration, Lake Success, NY). This revealed a Grade 2/4 pharyngeal hyperplasia with blood flecking on the nasopharyngeal walls. There was a green-yellow discharge adherent to the right guttural pouch opening. The larynx was symmetrical with normal "slap test" and direct stimulation reflexes. A

Fig 2 Endoscopic view of the left guttural pouch showing an oval defect in the medial septum and a view of the contralateral pouch after successful treatment.

Endoskopische Ansicht des linken Luftsacks mit einem ovalen Defekt im medialen Septum und Blick auf den kontralateralen Luftsack nach erfolgreicher Behandlung.

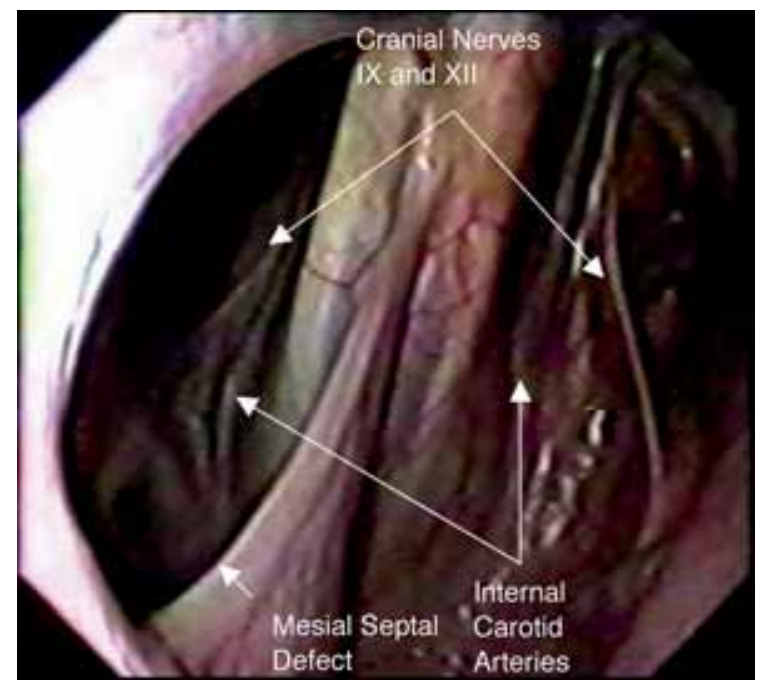

muco-purulent exudate was found at the thoracic inlet. A trans-tracheal wash was performed for cytological and microbiological examination, which revealed evidence of bacterial lower airway disease. Examination of the left guttural pouch revealed a yellow-green mass firmly attached to the dorsorostral surface of the medial septum. Dorsal to the mass, there were several small diffuse white plaques. The "strap-muscles" of the neck, (longus capitis, rectus capitis ventralis and rectus capitis lateralis) appeared affected, with multiple small ecchymotic hemorrhages adjacent to the mass. The mass was found localised to these structures and not found on the internal, external or maxillary arteries along their course over the guttural pouches. A biopsy of the mass was taken through the endoscope. Examination of the right guttural pouch revealed similar findings with a more extensive mass and tissue necrosis of the medial septum (Figure 1). A pool of yellow-green cloudy fluid was present on the medial compartment floor. Microscopic examination of the biopsy revealed fungal hyphae with Rhizopus spp and Aspergillus nidulans isolated on culture. Preliminary diagnosis was bacterial lower airway disease with atypical guttural pouch mycosis.

Treatment involved sedating the horse with $100 \mathrm{mg}$ xylazine ${ }^{a}$ and installing a 30 French Foley catheter under endoscopic guidance into the right guttural pouch. The pouches were then flushed with $60 \mathrm{ml}$ of a $1.7 \%$ enilconazole $^{b}$ solution. After 12 hours, the right Foley catheter became disengaged from the guttural pouch and was replaced on two subsequent occasions under sedation with $1.0 \mathrm{ml}$ butorphanol tartratec and $0.5 \mathrm{ml}$ detomidine hydrochlorided. Eventually, a $10 \mathrm{FG}$ spiral catheter was placed into each guttural pouch. On Day 4 , swelling was noted in the area of the retropharyngeal lymph nodes with excessive mucus production in the pouches. These changes were thought to be induced from the indwel- 
ling catheters, which were subsequently removed. The enilconazole therapy, on a once daily basis (for 4 more days), was continued using a flushing catheter through the endoscope.

The horse was initially treated with oxytetracycline $(10 \mathrm{mg} / \mathrm{kg})$ IM every other day. After two doses, a myositis developed from the IM injections and the horse was subsequently switched to trimethoprim sulfa $(15 \mathrm{mg} / \mathrm{kg})$ PO BID for ten days. The horse was also treated with phenylbutazone $\mathrm{e}$ i/v $(2.4$ $\mathrm{mg} / \mathrm{kg}, 1.1 \mathrm{mg} / \mathrm{lb})$ followed by $\mathrm{PO}, \mathrm{BID}(2.4 \mathrm{mg} / \mathrm{kg}, 1.1$ $\mathrm{mg} / \mathrm{lb})$ for two days, reducing to $1 \mathrm{gm} P O, Q D$ for 3 days. Endoscopy of the pouches on the ninth day revealed an approximate $50 \%$ reduction in size of the fungal plaques. There was soft devitalised tissue present on the medial septum previously covered by the plaque. There were no fungal elements seen on wet preparation of the guttural pouch samples. The filly was discharged on Day 10, for a period of two weeks after which time she represented for further evaluation (Day 24). Guttural pouch endoscopy revealed the mucosa overlying both pouches to be clear of infection. The medial septum had been eroded by the fungus such that the contralateral pouch could be entered both dorsal and ventral to a fungal mass that was attached rostral and caudal by a thin strip of tissue. These attachments were released using the grab-biopsy instrument. A Foley catheter was passed into the left pouch and a liter of sterile $0.9 \%$ sodium chloride was pumped in, flushing the detached mass into a collection jar. The edges of the remaining oval deficit were covered with $1.7 \%$ enilconazole. A final examination was performed nine weeks (Day 63) after the initial diagnosis. The filly was gaining weight and had begun training satisfactorily. On physical examination there was no evidence of lower airway disease. Guttural pouch endoscopy showed clinically healthy tissue surrounding the incomplete medial septum (Figure 2).

\section{Case 2}

A 12-year-old, 467kg (1027-lb.) Thoroughbred gelding was presented to WCVM with a one-month history of Streptococcus equi infection, characterised by swollen submandibular lymph nodes, bilateral nasal discharge and respiratory stertor. The horse had been treated with phenylbutazone $(4.2 \mathrm{mg} / \mathrm{kg}$, $1.95 \mathrm{mg} / \mathrm{lb}) \mathrm{PO}$ BID for two days and procaine penicillin $\mathrm{G}^{f}$ $(28,910 \mathrm{IU} / \mathrm{kg}, 13,145 \mathrm{IU} / \mathrm{lb}), \mathrm{IM}$ BID for four days.

On follow-up examination, the horse was sedated using 200mg xylazine hydrochloride ${ }^{a}$ IV and upper airway endoscopy performed. This revealed swelling and hyperemia of the nasopharyngeal tissues with a reduction in nasopharyngeal diameter. Guttural pouch openings were normal and a small volume of mucopurulent debris was seen in the trachea. Examination of the left guttural pouch revealed retropharyngeal lymph node enlargement. In the right guttural pouch, the mucosal surface overlying the stylohyoid bone was covered in a diphtheritic membrane dorsally and medially. No other structures were involved. A provisional diagnosis of atypical guttural pouch mycosis was made and a biopsy was taken for cytology and microbiological examination.

Cytology revealed large clumps of poorly stained fungal hyphae and mats of mixed bacteria. Fungal hyphae had parallel sides with septate suggesting Aspergillus spp., however sexual parts were not evident. There were also rare pigmented hyphae and spores consistent with Alternaria spp. Culture of the fungal elements revealed Penicillium spp., Mucor spp., Chrysosporium spp., and Alternaria spp. No S. equi was identified on bacterial culture.

Treatment involved daily endoscopy to insert an artificial insemination pipette placed into the right pouch and infusing 30 $\mathrm{ml}$ of $0.9 \%$ enilconazole $\mathrm{e}^{\mathrm{b}}$ once a day for five days. The horse was discharged into the care of the owner (Day 5).

The horse was examined 14 days later (Day 19) and endoscopy revealed the initial fungal lesion to be narrow, but expanded caudally. There was also a new mass on the ventral floor of the medial compartment that did not involve cranial nerves or blood vessels. The horse was sedated as before and treated daily with $30 \mathrm{ml}$ enilconazoleb via the endoscope. Before each treatment, biopsy instrumentation was used to tease the mass in an effort to lift it off the floor of the compartment. After three days (Day 22) the rostral part of the mass was removed using this technique. Treatment was continued daily for an additional ten days (Day 32). Throughout this time careful debridement of the mass was undertaken. After 32 days, the lesion was no longer present and the horse was discharged.

\section{Case 3}

A 13-year-old, 400kg (880-lb.) Quarter horse mare was referred to WCVM for a suspected esophageal obstruction. The horse was febrile (38.8 C, 101.8 F), with a normal heart and respiratory rate. There was a foul smelling, bilateral mucopurulent nasal discharge with feed material. Thoracic auscultation using a rebreathing bag revealed no abnormalities. Chest percussion did not reveal a fluid line or pleurodynia. Cardiac auscultation was unremarkable. The horse appeared clinically dehydrated (6-8\%) based on prolonged skin tent and tacky mucous membranes.

Endoscopic examination of the upper respiratory tract was performed under sedation. This revealed feed material in the ventral and middle meatus, bilaterally. Mucus and feed material were present within the nasopharynx, and persistent dorsal displacement of the soft palate (DDSP). The larynx was asymmetrical with a Grade 4 right laryngeal hemiplegia. A small amount of feed material was found in the trachea. A trans-tracheal wash revealed findings consistent with oropharyngeal contamination. A complete blood count revealed leukopenia, $\left(3.5 \times 10^{9} / \mathrm{L}\right.$; reference range $\left.5.5-12.5\right)$ and neutropenia, $\left(1.68 \times 10^{9} / \mathrm{L}\right.$; reference range 2.7 - 6.7). Fibrinogen was $5 \mathrm{~g} / \mathrm{L}$, (reference range $0-5 \mathrm{~g} / \mathrm{L}$ ). Hematocrit was normal (41.7\%; reference range $32-52)$ and total protein was elevated, $(81 \mathrm{~g} / \mathrm{L}$; reference range 60-77).

Endoscopic examination of the left guttural pouch revealed a yellow-green mass firmly attached to the dorso-rostral surface of the "strap-muscles" of the neck. There were a few ecchymotic hemorrhages adjacent to the mass. The medial septum separating the two pouches was obliterated by the mass such that the medial compartment of the right pouch could be visualized from the left side. There was some red- 
dening of the mucosa on the caudal aspect of the medial compartment at the level of cranial nerves IX and XII.

The floor of both medial compartments were covered rostrally by the fungal plaque. None of the vascular structures were involved in either pouch. Trans-endoscopic washes of both guttural pouches were performed and fungal elements of an Alternaria spp. were observed on direct examination, but could not be cultured. Culture revealed a mixed bacterial population with no evidence of $\mathrm{S}$. equi. A diagnosis of atypical guttural pouch mycosis was made with neurological deficits (neurogenic dysphagia). Endoscopic examination of the esophagus revealed no abnormalities and no recent obstruction.

Treatment involved placing a catheter through the biopsy channel of the endoscope and infusing $60 \mathrm{ml}$ of a $1.7 \%$ enilconazole $^{b}$ solution directly onto the mycotic lesions. A 14G over-the-needle catheter was placed in the right jugular vein and 21 liters of Lactated ringers solution was administered intravenously. The horse was also given $15 \mathrm{mg} / \mathrm{kg}(6.8 \mathrm{mg} / \mathrm{lb})$ trimethoprim sulfag IV BID for 6 days and 1.5 grams of phenylbutazone ${ }^{\mathrm{e}}$ IV QD.

The pouches were monitored via endoscopy and treated as above on a daily basis. On Day 2, the fungal plaque on the dorso-rostral aspect of the strap muscles was reduced in size and a large portion of this could be removed using biopsy forceps. The caudal aspect of the pouch was still hyperemic. By Day 6, intermittent DDSP indicated improvement in soft palate function. Inflammation in both pouches was resolving and the fungal plaque could no longer be appreciated. Movement of the right arytenoid cartilage (Grade 3/4) was noted on Day 8 and a slap test was positive bilaterally. By Day 9, there was no evidence of mucopurulent exudate or feed material at the nares and the horse was discharged.

A follow-up examination was performed on Day 39 at which time the mare's weight had fallen to $347 \mathrm{~kg}$ (764lbs). Endoscopic examination revealed a Grade 4 right laryngeal hemiplegia and DDSP. Endoscopy of the right guttural pouch revealed no evidence of fungal plaques or inflammation. However, an area of shiny grey-white tissue was seen to encompass cranial nerves IX and XII as they moved horizontal. This tissue was interpreted as scar tissue and considered to be the cause of the neurological deficits.

The horse was returned for a final examination on Day 142. The mare had gained weight $416 \mathrm{~kg}$ (915lbs). The owner reported that the mare had been improving, but with intermittent nasal discharge and no coughing. Bilateral mucoid green tinged nasal discharge was noted on physical examination. An upper airway endoscopic examination revealed that the left ventral meatus contained a small amount of feed material. The soft palate was in the correct position, displaced during swallowing but not replaced. No asynchrony in the movement of the arytenoids was noted. Examination of the right pouch revealed that the lower portion of the medial compartment was constricted by a tight band of shiny-white tissue encompassing cranial nerves IX and XII. The horse was discharged and the owner declined any further re-examinations. However, telephone follow-up ( 3 and 6 months) revealed improvements in the horse's health and a cessation of nasal discharge.

\section{Discussion}

The cases presented are novel, in that the fungal plaque was not associated with a major artery traversing the guttural pouch and epistaxis was not a clinical sign. Only in one other incidence was passing mention to this phenomenon noted (Lane and Mair 1987). Typically, guttural pouch mycosis is not diagnosed until dramatic clinical signs (e.g. epistaxis, pharyngeal paralysis) are seen, by which time a well-developed mycotic plaque is usually present (ie. an acute presentation for a chronic condition). Incidental findings of mycosis have been reported at necropsy (Cook 1971), however there are no published ante-mortem reports of a developing fungal plaque prior to epistaxis.

The pathogenesis of guttural pouch mycosis has not been fully determined and much has been extrapolated from case reports and case series. Proposed etiologies include:

Initial inflammation of the tubal mucosa as part of an upper respiratory infection blocking the tympanic opening leading to a secretory otitis media and posterior bacterial invasion. Secretory otitis could produce a serous discharge into the guttural pouch providing an ideal culture medium for ever-present fungal spores (Floer 1972).

A pre-existing arterial aneurysm resulting in serous or blood leakage, providing an ideal culture media for the establishment of a mycotic plaque (Cook 1979).

Deep penetration of the fungus causing thrombo-arteritis and arterial aneurysm leading to hemorrhage (Cook et al., 1968b), as Aspergillus have a tendency to invade blood vessels (Rinaldi 1983).

The significance of the fungal plaque in gutturomycosis is uncertain. It appears that the fungal plaque can spontaneously disappear over a variable time course (Freeman 1999), after the affected artery is properly occluded (Speirs et al., 1995) with, or without additional specific anti-fungal treatments. The premise being that this starves the fungal plaque resulting in its death (Lane 1989). These varying treatment options question the premise that the advancing mycotic plaque requires an intact blood supply to support its' growth since it is unlikely that vascular compromise leads to spontaneous regression.

The cases presented in this series demonstrate the destructive potential of an advancing mycotic plaque. Of all the mycotic organisms, aspergillosis encompasses the broadest range of pathogenic mechanisms, where tissue boundaries offer little resistance to the spread of invasive Aspergillus hyphae (Chandler and Watts 1987). Aspergillus spp. are the most common fungi encountered in human infections, whereby ability to evoke disease depends on the local or general physiologic and immunologic state of the host (Rinaldi 1987).

The most successful treatment of guttural pouch mycosis is surgical ligation or occlusion of the affected artery. This is most often performed when episodes of epistaxis have occurred. Surgical ligation (Owen and McKelvey 1979), balloontipped (Freeman et al. 1989) or micro-coil occlusion (Léveillé et al. 2000) of the affected blood vessels to prevent fatal hemorrhage. Complications associated with surgical arterial 
occlusion include multifocal cerebro-cortical necrosis, blindness (Hardy et al. 1990), Horner's syndrome, and post-operative epistaxis (Greet 1987; Caron et al. 1987). Another potential cause of epistaxis is recanalization / neovascularization at the embolization sites (Léveillé et al. 2000).

If medical therapy alone is instigated, it is likely to be prolonged (4 - 6 weeks) and expensive (Hawkins 1992). Little is available to treat Aspergillus infections and even less is known about efficacy for guttural pouch mycosis or if fungicidal solutions themselves would damage guttural pouch membranes. The value of such therapy is difficult to ascertain because of the lack of controlled clinical trials and rare occurrence of guttural pouch mycosis. Treatment options include thiabendazole (Jacobs and Fretz 1982; Smith and Barber 1984; Walmsley 1988), iodides (Mcllwraith 1978; Owen and McKelvey 1979), miconazole (Lane 1980), nystatin (Church et al. 1986), and natamycin (Greet 1987). Povidone iodine in a 5 - 10\% solution has been used but minimal information is available about its efficacy against fungi growing in tissue (Hawkins 1992). Raker (1976) claims to have effectively treated cases of mycosis with a $25 \%$ dilution of povidone iodine solution into the guttural pouch. Van Nieuwstadt et al. (1994) claim success against an A. fumigatus pouch infection by lavaging the pouch twice daily for three weeks with a $1 \%$ solution of enilconazole. In another case, daily treatment with a $3.3 \%$ enilconazole solution using indwelling catheters resulted in a clinical cure (Davis and Legendre 1994). Nystatin, natamycin and miconazole are said to have little efficacy against Aspergillus, where Amphotericin B is the drug of choice but its' usefulness is limited by its' toxicity in the horse (Freeman 1999). Adequate contact time between a topical anti-fungal agent and mycotic plaque is necessary for successful treatment, but this is typically difficult since the mycotic plaque lies dorsally in the guttural pouch.

In the opinion of these authors, with no history of epistaxis and no major vessel underlying the mycotic plaques, there was little choice but to attempt medical treatment in these three cases. These decisions were based on daily endoscopic evaluations of the cases, revealing an aggressive advancing fungal plaque. Daily endoscopic evaluation with careful debridement and flushing was the preferred option, as chemical restraint was not necessary. Debridement was only attempted in areas where the plaque appeared to be dying and lifting off the guttural pouch mucosa. Caution should be exercised since the fungal plaque could still be vascularized by an aberrant vessel (Hardy et al. 1990). If the fungal plaque involved any major artery then debridement should not be attempted. Enilconazole was chosen in these cases due to its strong, broad-spectrum fungicidal effect. It has an active vapour phase (Davis and Legendre 1994) that allows the drug to spread and remain active for a long period of time. In addition, the commercial preparation had a sticky viscous quality allowing the solution to stick to the fungal plaque.

Despite the ease of treatment using retention catheters, the inflammation and increased mucus production associated with their use (Wilson 1995) was unacceptable. Due to the random placement of the spiral catheters within the guttural pouch, it is very likely that the instilled solution did not contact the fungal plaque and that rapid drainage from the pouch prevented action of the active vapour phase.
The medical therapy chosen in these cases proved to be effective with persistence, debridement and close monitoring. Pharyngeal paralysis due to guttural pouch mycosis is often associated with a poor prognosis and euthanasia. Case 3 consistently demonstrated some degree of pharyngeal paralysis which improved mildly post-treatment given the horse's weight gain and limited ability to correctly replace the soft palate in its' normal anatomical location. Recent work suggests that not all cases of pharyngeal paralysis due to sof palate dysfunction are hopeless (Holcome et al. 1998). If the inciting was pharyngeal plexus inflammation/dysfunction then enough segments of the pharyngeal plexus may recover and restore soft palate function.

These cases underline the importance of routine examination of both guttural pouches in cases of airway disease, spontaneous epistaxis or pharyngeal paralysis.

\section{Manufacturers addresses}

a) Rompun 100, 100mg/ml, Bayer Inc, Agriculture Division, Toronto, ON. M9W1G6.

b) Imaverol 10\%, Janssen Pharmaceutica, Mississauga, Ontario L5N 5R9

c) Torbugesic, $10 \mathrm{mg} / \mathrm{ml}$, Ayerst Laboratories, Montreal, Canada.

d) Dormosedan, 10mg/ml, Pfizer Canada Inc, 635 Wilton Grove Road, London, ON. N6N1N7

e) Phenylbutazone, $200 \mathrm{mg} / \mathrm{ml}$, Vetoquinol Inc, 2000 Chemin Georges Lavaltrie, Quebec. JOK1HO

f) Ethacillin, 300,000IU/ml, rogar/STB Inc, 635 Wilton Grove Road, London, ON. N6N1N7

g) Nu-Cotrimox-DS, 960mg tablets, Nu Pharm Inc, Rich mond Hill, Ontario, Canada

\section{Literature}

Baptiste K. E., Naylor J. M., Bailey J., Barber S. M., Post K. and Thornhill J. (2000). A function for guttural pouches in the horse. Nature 403, 382-3

Biorklund N. E. and Palsson G. (1970): Guttural pouch mycosis in the horse. A survey of seven cases and a case report. Nord. Vet. Med 22, 65-74

Brandt J. F. (1863): Bericht über eine Abhandlung, Untersuchung der Gattung Hyrax in anatomischer und verwandtschaftlicher Beziehung. Bull. Acad. Imp. Sci. (St. Petersburg), 5, 508-510

Caron J. P., Fretz P. B., Bailey J. V., Barber S. M. and Hurtig M. B. (1987): Balloon-tipped catheter arterial occlusion for prevention of haemorrhage caused by guttural pouch mycosis: 13 cases (1982-1985). J Am Vet Med Ass 191, 345-349

Chandler F. W. and Watts J. C. (1987): Pathological Diagnosis of Fungal Infections. pp. 55-73. Chicago: American Society of Clinical Pathologists Press

Church S., Wyn-Jones G., Parks A. H. and Ritchie H. E. (1986): Treatment of guttural pouch mycosis. Equine Vet J. 16, 121-124

Cook W. R. (1966). Observations on the aetiology of epistaxis and cranial nerve paralysis in the horse. Vet Rec 78, 396-405

Cook W. R. (1968): The clinical features of guttural pouch mycosis in the horse. Vet Rec 83, 336-345

Cook W. R., Campbell R. S. and Dawson C. (1968b): The pathology and aetiology of guttural pouch mycosis in the horse. Vet Rec $83,422-8$ 
Cook W. R. (1971): Diseases of the ear, nose and throat in the horse. In: Veterinary Annual vol 12, ed. C.S.G.Grunsell, pp 12-43. Bristol: John Wright

Cook W. R. (1979): Mycotic aneurysms of the guttural pouch: Diagnosis and treatment. New Zealand Veterinary Journal. 27, 51

Davis E. W. and Legendre A. M. (1994): Successful treatment of guttural pouch mycosis with Itraconazole and topical Enilconazole in a horse. J Vet Int. Med. 8, 304-305

Dixon P. M. and Rowlands A. C. (1981): Atlanto-occipital joint infection associated with guttural pouch mycosis in a horse. Equine Vet J 13, 260-262

Engelke E., Wenthe M., Wißdorf H. and Waibl H. (1997): Anatomische Grundlagen und endoskopische Befunde zum Öffnungsvorgang der Tuba auditiva des Pferdes. Pferdeheilkunde 13, 639-646

Floer W. (1972): Untersuchungen uber die Mikroflora des Luftsäk-

kes beim Pferd. Inaugural Dissertation, Tierarztliche Hochschule, Hannover. 40pp

Freeman D. E., Ross M. W., Donawick W. J. and Hamir A. N. (1989): Occlusion of the external carotid and maxillary arteries in the horse to prevent hemorrage from guttural pouch mycosis. Vet Surg 18,39-47

Freeman D. E. (1980): Diagnosis and treatment of diseases of the guttural pouch Part 1. Compend Contin Educ Pract Vet 1, 3-1 1

Freeman D. E. (1999): Guttural pouch. In: Equine Surgery 2nd Edition. ed Auer JA and Stick JA. P371. Philadelphia: W.B. Saunders Co.

Grabner A. (1987): Diagnose und therapie der Luftsackmykosen des Pferdes. Tier Praxis Suppl 2, 10-14

Greet T. R. C. (1987): Outcome of treatment in 35 cases of guttural pouch mycosis. Equine Vet. J 19, 483-487

Gresti de A., Barone P. and Perniola N. (1993): Un caso di micosi delle tasche gutturali causato da Aspergillus ochraceus: diagnosi e terapia [A case of guttural pouch mycosis caused by Aspergillus ochraceus : diagnosis and therapy.] Ippologia 4, 81-86

Guillot J., Ribot X., Cadore J. and Bornert G. ( 1996): L'aspergillose des poches gutturales des equides. Bull. Soc. Vet. Prat. de France $80,141-162$

Hardy J., Robertson J. T. and Wilkie D. A. (1990). Ischemic optic neuropathy and blindness after arterial occlusion for treatment of guttural pouch mycosis in two horses. J Am Vet Med Assoc. 196, $1631-1634$

Hatziolos B. C., Sass B., Albert T. F. and Stevenson M. C. (1975): Ocular changes in a horse with gutturomycosis. J Am Vet Med Assoc 167, 51-54

Hawkins D. L. (1992): Diseases of the guttural pouches. In: Current Therapy in Equine Medicine. ed. Robinson N. E. pp 275-280. Sydney: W. B. Saunders Co.

Hinchcliffe R. and Pye A. (1969): Variations in the middle ear of the mammalia. J. Zool.(London) 157, 277-288

Holcome S. J., Derksen F .J., Stick J. A. and Robinson N. E. (1998): Effect of bilateral blockade of the pharyngeal branch of the vagus nerve on soft palate function in horses. Am J Vet Res 59, 504-508

Jacobs K. A. and Fretz P. B. (1982): Fistula between the guttural pouches and the dorsal pharyngeal recess as a sequela to guttural pouch mycosis in the horse. Can Vet J 23, 117-118

Johnson J. H., Merriam J. G. and Attleberger M. (1973): A case of guttural pouch mycosis caused by Aspergillus nidulans. Vet Med Small Animal Clin. 68, 771-774

Kipar A. and Frese K. (1993): Hypoglossal neuritis with associated lingual hemiplegia secondary to guttural pouch mycosis. Vet Pathol 30, 574-576

Lane J. G. and Mair T. S. (1987): Observations on headshaking in the horse. Equine Vet J 19, 331-36

Lane J. G. (1980): The combination of surgery and medication with imidazole derivatives for the treatment of mycotic infections. Proc Ass Vet Clin Pharm Therap 4, 82-86

Lane J. G. (1989): The management of guttural pouch mycosis. Equine Vet J 21, 321324
Léveillé R., Hardy J., Robertson J. T., Willis A. M., Beard W. L., Weisbrode S. E. and LePage O. M. (2000): Transarterial coil embolization of the internal and external carotid and maxillary arteries for prevention of hemorrhage from guttural pouch mycosis in horses. Vet Surg 29, 389-397

Mcllwraith C. W. (1978): Surgical treatment of acute epistaxis associated with guttural pouch mycosis. Vet Med Small Anim Clin 73, 67-69

McLaughlin B. G. and O'Brien J. L. (1986): Guttural pouch mycosis and mycotic encephalitis in a horse. Can Vet J 27, 109-111

Otto B., Ohnesorge B., Wissdorf H. and Übermuth K. (1995): Beitrag zur topographie der endoskopisch sichtbaren strukturen im bereich des luftsacks. Pferdeheilkunde 1 1, 35-41

Owen R. and McKelvey W. A. C. (1979). Ligation of the internal carotid artery to prevent epistaxis due to guttural pouch mycosis. Vet. Rec. 104, 100-101

Raker C. W. (1976): Diseases of the guttural pouch. Mod Vet Pract 57, 549-552

Rawlinson R. J. and Jones R. T. (1978): Guttural pouch mycosis in two horses. Aust Vet J 54, 135-138

Rinaldi M. G. (1983): Invasive aspergillosis. Rev Infect Dis. 5, 1061 77

Ryan J.A., Modransky P .D. and Welker B. (1992): Guttural pouch myco sis in a 3-month-old foal. Equine Practice 14, $21-22$

Smith K. M. and Barber S. M. (1984): Guttural pouch hemorrhage associated with lesions of the maxillary artery in two horses. Can Vet. J 25, 239-242

Speirs V. C., Harrison I. W., Van Veenendaal J. C., Baumgartner T., Josseck H. H. and Reutter H. (1995): Is specific antifungal therapy necessary for the treatment of guttural pouch mycosis in horses. Equine Vet J 27, 151-152

Turner H. N. (1850): Contributions to the anatomy of the tapir. Proc. of Zool. Soc.(London) 102-106

Van Nieuwstadt R. A. and Kalsbeek H. C. (1994): Luchtzakmycose: Lokale behandeling via een permanente catheter met enilconazol. [Air sac mycosis: topical treatment using enilconazole administered via indwelling catheter]. Tiidschr Diergeneeskd 1 19, 3-5

Wagner P. C., Miller R. A., Gallina A. M. and Grant B. D. (1978): Mycotic encephalitis associated with a guttural pouch mycosis. J Equine Med Surg 2, 335-339

Walmsley J. P. (1988): A case of atlanto-occipital arthropathy following guttural pouch mycosis in a horse. The use of radioisotope scanning as an aid to diagnosis. Equine Vet J 20, 219-220

Wilson J. (1985): Effects of indwelling catheters and povidone iodine flushes on the guttural pouches of the horse. Equine Vet J 17, 242-244

\section{Acknowledgements}

The authors would like to thank Drs. Clark, Fryer, Townsend and Naylor for the diagnosis and management of Case 2.

James L Carmalt MA, VetMB, MVetSc, Diplomate ABVP

Department of Large Animal Clinical Services

Western College of Veterinary Medicine

University of Saskatchewan

52 Campus Drive

Saskatoon, SK S7N 5B4, Canada 